\title{
FOXP3 Modulation of Quercetin-3-O-rhamnoside and its Impacts on Lupus Nephritis Mice
}

\author{
Niken Indriyanti" ${ }^{*}$, Joewono Soeroso ${ }^{2}$, Junaidi Khotib ${ }^{3}$ \\ 'Department of Pharmacology, Faculty of Pharmacy, Mulawarman University, Samarinda, East Kalimantan, INDONESIA. \\ ${ }^{2}$ Department of Internal Medicine, Faculty of Medicine, Universitas Airlangga, Jl. Prof. Dr. Moestopo, Surabaya, East Java, INDONESIA. \\ 3 Department of Clinical Pharmacy, Faculty of Pharmacy, Universitas Airlangga, J. Dharmawangsa Dalam, Surabaya, East Java, INDONESIA.
}

\begin{abstract}
Background: Quercetin-3-O-rhamnoside (QUE) has anti-inflammatory and anti-oxidative effects which probably beneficially used in lupus. Objective: This research was focused on analyzing the effects of QUE on FOXP3 modulation to result in an anti-inflammatory outcome in the kidney of severe lupus mice. Methods: This research used Pristane-induced female BALB/c lupus mice, and the biomarkers involved in were $\mathrm{CD} 4{ }^{+} \mathrm{CD} 25^{+} \mathrm{T}$ reg cells, FOXP3 T cells, anti-Sm, IL-6, and histopathology assessment of the kidney of lupus mice. The QUE group was treated and compared to the negative control which received placebo, and the positive control which received cyclophosphamide. Results: QUE increased the number of $\mathrm{CD}^{+}{ }^{+} \mathrm{CD} 25^{+}$ T reg cells (negative control: $3.01 \pm 3.43 \%$; QUE: $18.77 \pm 5.12 \%$; positive control: $3.26 \pm 11.09 \%)$, and FOXP3 significantly $(p<0.05)$ (negative control: 1.14 $\pm 0.54 \%$; QUE: $2.00 \pm 1.45 \%$; positive control: $1.73 \pm 1.14 \%$ ). The antiSm level did not decrease, meanwhile the IL-6 decreased significantly, and the histopathological assessment of the kidney reveal the repairing effects of QUE on glomeruli. Conclusion: QUE has an anti-inflammatory activity which reduces the severity of lupus nephritis signs in lupus mice by initially
\end{abstract}

increasing the $\mathrm{CD}^{+}{ }^{+} \mathrm{CD} 25^{+}$and $\mathrm{FOXP3}{ }^{+}$Tregs numbers. $\mathrm{QUE}$ is potential to be further developed as a safe treatment choice for lupus nephritis.

Key words: Glomerulonephritis, IL-6, Lupus, Pristane, T regs.

Key message: The efficacy of QUE as a safe drug on lupus mice was proven dominantly by modulating the $\mathrm{CD} 4{ }^{+} \mathrm{CD} 25+\mathrm{FOXP} 3^{+} \mathrm{T}$ regs, so that the IL-6 and the glomerulonephritis decreased significantly.

Correspondence

Niken Indriyanti, Faculty of Pharmacy, Mulawarman University, Penajam Road, Gunung Kelua College of Mulawarman University, East Kalimantan Province, INDONESIA.

Phone: +62541739491

Email: niken@farmasi.unmul.ac.id

DOI: 10.5530/jyp.2018.10.41

\section{INTRODUCTION}

Quercetin is a single compound that was expected to be effective to treat severe lupus manifestations because of its well-known anti-inflammatory ${ }^{1}$ and anti-oxidative effects. ${ }^{2}$ This compound is predicted as an active marker of many medicinal plants which are examined as more safe, useful, and promising for lupus than the current treatments. Quercetin is also suppressing the manifestations of rheumatoid arthritis, a kind of autoimmune disease in rat model induced by using Complete Freund's Adjuvant (CFA) and collagen. However, there is no data about the effect of quercetin on lupus.

In this research, we challenged quercetin in the form of its O-glycoside, named quercetin-3-O-rhamnoside (QUE) to determine its efficacy on lupus mice induced by using Pristane. The $\mathrm{O}$-glycoside form was chosen because it has a better solubility than its aglycone, ${ }^{3,4}$ so the QUE will be absorbed better. The QUE better absorption profile supports the advantage of QUE which has lower side effects in usual dose and in a long-term lupus treatment, compared to the current treatments. However, the effect of QUE needs to be analyzed by a series of lupus biomarkers. In this case, aligned to its anti-inflammatory effect, we chose the T cell-dependent pathway of lupus pathogenesis which consists of $\mathrm{T}$ regs $\left(\mathrm{CD} 4{ }^{+} \mathrm{CD} 25^{+}\right.$ T cells and FOXP3 $^{+}$T cells), anti-Smith (anti-Sm) antibody, IL-6, and the histopathology assessment of the kidney of lupus mice. Lupus mice which induced by using Pristane is an appropriate lupus model which reveals severe lupus signs as human lupus. ${ }^{5,6}$ Therefore, this study aimed to determine the QUE effects on T cell-dependent pathway biomarkers of lupus pathogenesis on lupus nephritis mice, which focused on FOXP3 modulation at the initial phase.

\section{MATERIALS AND METHODS}

\section{Materials}

Quercetin-3-O-rhamnoside (QUE) was obtained from a Sigma-Aldrich distributor in Singapore. The female BALB/c mice aged four weeks which were stated as Species Pathogen Free (SPF) were purchased from the animal breeding of LPPT Unit 4, Gadjah Mada University, and then housed in animal laboratory of Faculty of Pharmacy, Universitas Airlangga under standard conditions. Pristane, a chemical to induce lupus mice was obtained from Sigma Aldrich. Anti-CD4, anti-CD25, anti-FOXP3, and anti-IL-6 were purchased from Biogenesis USA via Laboratory of Molecular Biology, Brawijaya University. Anti-Sm ELISA kit for mice was obtained from Cusabio. The chemicals used for hematoxylin-eosin staining was provided by the Laboratory of Veterinary Medicine, Universitas Airlangga.

\section{Methods}

Thirty female BALB/c mice with severe lupus nephritis signs (which previously injected by using Pristane) were calculated by considering the standard of deviation of our previous study. ${ }^{5,6,7}$ They were randomized and divided into three experimental groups that consist of 10 mice per group: a negative control group which received placebo, a QUE group which received quercetin-3-O-rhamnoside at a dose of $21 \mathrm{mg} / \mathrm{kgBW}^{2}$, and a positive control group which received cyclophosphamide at a dose of $1 \mathrm{mg} / \mathrm{kg}$ BW. In fact, cyclophosphamide is used as an off-label drug for lupus. It has a probable nephrotoxic side effect, so that we used other reference. We tested three healthy mice as a comparison only for kidney tissue parameter, but not included in the experimental group. 
The treatments lasted for 21 days. At the end of the experiment, we performed an intra-cardiac injection to take the maximum volume of whole blood of each mouse. The serum of each mouse was used to examine the anti-Sm and 8-OHdG level by using ELISA kits. Then, the mice were sacrificed by cutting their aorta. The mice spleens and bone marrow were suddenly prepared and analyzed as the flow cytometry samples in the phosphate buffer saline (PBS). The fluorescence staining was done by using phycoetrin (PE). Finally, the kidneys and the joints were isolated and then prepared well to become $4-6 \mu \mathrm{m}$ thickness of histological specimens for hematoxylin-eosin (HE) staining. The microscopic observation of the kidney was done by using a light microscope (Nikon Eclipse $\mathrm{Ci}$ ) at a magnitude of 400x, and then the joint inspection was done by using Optilab microscope at a magnitude of 40x. The histopathology assessment was done by performing semi-quantitative analysis by following Moroni's method (kidney assessment). All the data were analyzed by facilitating of SPSS statistics. The ethical clearance of this research was certified by an ICUC of Faculty of Veterinary Medicine, Universitas Airlangga with the number of 512-KE.

\section{RESULTS}

The female BALB/c mice used in all experimental groups of this study were severe lupus mice which indicated by the high protein level in the urine $( \pm 100 \mathrm{mg} / \mathrm{dL})$. Their body weights were 20 -35 g before the treatments started. We randomized the three groups based on body weight, so that we obtain the homogenous baseline between experimental groups. QUE has high anti-inflammatory and antioxidant activities. Its antiinflammatory effect correlates to $\mathrm{T}$ regulatory ( $\mathrm{T}$ reg) cells. A T reg which plays a crucial role in repairing autoimmune condition is $\mathrm{CD} 4{ }^{+} \mathrm{CD} 25^{+} \mathrm{T}$ reg cells (Figure 1). QUE increase the relative percentage of $\mathrm{CD} 4^{+} \mathrm{CD} 25^{+}$ $\mathrm{T}$ reg cells significantly $(p<0.05)$. It means that the higher $\mathrm{CD} 4^{+} \mathrm{CD} 25^{+} \mathrm{T}$ cells will maintain the balance of immune responses in lupus mice and predicted to reduce the systemic inflammation in severe lupus. However, this activity was further validated by a T cell-specific biomarker, FOXP3 to avoid a false positive data. The FOXP3 relative percentage in the QUE group increased significantly $(p<0.05)$ (Table 1$)$, reveals the better immune response controlling activity. Quercetin has a high activity of antiinflammatory effect. The increase of $\mathrm{T}$ reg in this result reveals the inflammatory controlling effect and the regulation of lupus auto-reactive $\mathrm{T}$ cells, so that the inflammatory manifestations in lupus mice can be decreased. The lupus-inflammatory manifestations will decrease if $\mathrm{T}$ regs have its usual number and function. Inflammation in lupus is a result of immune complexes which consist of auto-antigens and auto-antibodies. There are a wide variety of lupus-specific antibodies. ${ }^{8}$ A lupus drug candidate is highly potential if it reduces anti-Smith (anti-Sm) antibody, which is the main antibody that affects the tyrosine kinase. ${ }^{9}$ Therefore, anti-Sm trigs the production of a lot of lupus-specific antibodies. In this study, we measured the anti-Sm level (Table 2) in the blood of each lupus mice. QUE did not reduce the anti-Sm level significantly. It indicates that the target site or the heat of QUE is dominantly in anti-inflammatory activity, not in immunosuppressive activity. This is also a limitation of the use of anti-Sm as an antibody biomarker of lupus which is not as specific as anti-dsDNA since anti-Sm is a general trigger for some lupus antibodies. However, anti-dsDNA measurement in this mice model is not a good choice because no more than $40 \%$ of all induced mice produce anti-dsDNA, but more than $80 \%$ of them have high concentration of anti-Sm. However, this result will be supported by the further research about the effect of QUE on some lupus-specific antibodies, such as anti-dsDNA, anti-histon, and anti-nucleosome.

In this study, the anti-inflammatory activity of QUE was measured by analyzing a pro-inflammatory cytokine, IL-6 (Table 3 ). The total IL-6 significantly decreased $(p<0.05)$. It indicates the lower signs of systemic

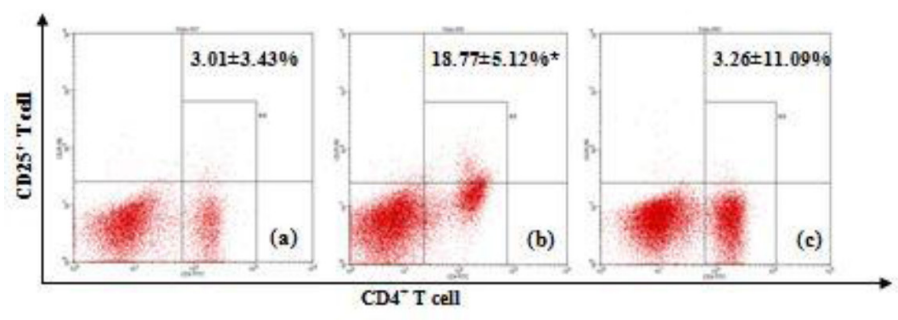

Figure 1: Profile of percentage of $C D 4^{+} C D 25^{+} T$ cells of the negative control group $(n=10)(a)$, QUE $(n=10)(b)$, and the positive control (cyclophosphamide) group $(n=10)$ (c) which measured from the mice spleen cells by using PE staining, by facilitating of a flow cytometer BD FACS Callibur and BD CellQuest program.

Table 1: Profile of the relative percentage of FOXP3 ${ }^{+} \mathrm{T}$ cells which was measured in the mice spleen cells of the three experimental groups by using PE staining in flow cytometer BD FACS Callibur which was supported by BD CellQuest program $(n=10)$.

\begin{tabular}{cc}
\hline Groups & FOXP3 $^{+}$T cells \pm SD (\%) \\
\hline Negative control & $1.14 \pm 0.54$ \\
QUE & $2.00 \pm 1.45^{\star}$ \\
Positive control & $1.73 \pm 1.14$ \\
\hline
\end{tabular}

*significantly different to the negative control group $(\mathrm{p}<0.05)$ using Oneway ANOVA calculation in SPSS Statistics

Table 2: The anti-Sm level in the blood of three tested groups after the treatment period $(n=10)$.

\begin{tabular}{cc}
\hline Groups & Anti-Sm level $(\mathrm{pg} / \mathrm{mL})$ \\
\hline Negative control & $109.93 \pm 12.02$ \\
QUE & $105.67 \pm 10.30$ \\
Positive control & $100.74 \pm 8.95$
\end{tabular}

The analysis result is not significantly different to the negative control group $(\mathrm{p}<0.05)$ using Oneway ANOVA calculation in SPSS Statistics

\begin{tabular}{|c|c|}
\hline Groups & IL-6+ \pm SD (\%) \\
\hline Negative control & $36.72 \pm 22.79$ \\
\hline QUE & $33.08 \pm 15.03^{*}$ \\
\hline Positive control & $3.57 \pm 9.97$ \\
\hline
\end{tabular}

* significantly different to the negative control group $(\mathrm{p}<0.05)$ using Oneway ANOVA calculation in SPSS Statistics

inflammation in the QUE groups compared to others. The lowering inflammation sign effect was directly observed in the kidney, the most influenced organ in severe lupus (Figure 2). In this case, the cyclophosphamide cannot be a golden standard since the nephrotoxicity side effect. $^{10,11}$ Therefore, the normal mice were used as the normal standard for this microscopic observation in the kidney assessment.

QUE reduces the inflamed glomerulus by reducing some histopathology indicators (Figure 2). The inflammatory cells deposit in the glomerulus of QUE group seems lower than the negative control group. The messangial tissue thickness did not decrease, but the Bowman's capsules look wider than the negative control group. These signs are beneficial to normalize the renal function in severe lupus mice. Beside glomerulus, 


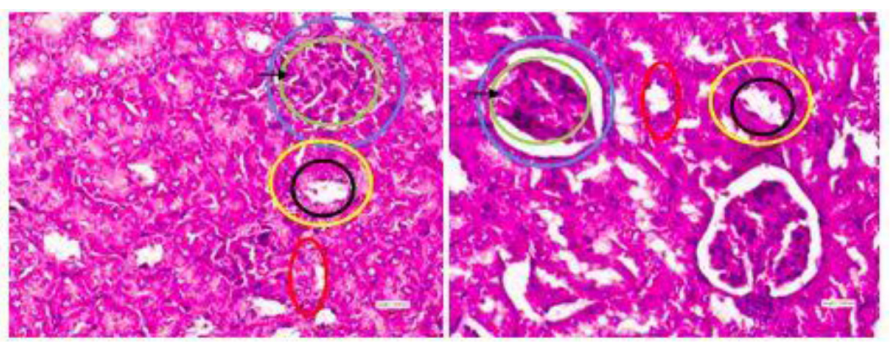

(a) Negative control (b) QUE

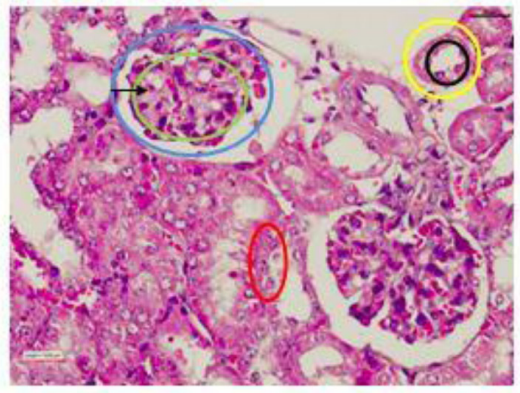

(c) Normal control

Figure 2: The histopathology observation of the negative control group (a) $(n=10)$, QUE $(b)(n=10)$, and normal control group (c) $(n=3)$ by facilitating of microscope Nikon Eclipse $\mathrm{Ci}$ at a magnitude of 400x. The samples were prepared into $4-6 \mu \mathrm{m}$ slides with $\mathrm{HE}$ is staining. The ruler indicates $10 \mu \mathrm{m}$ in length. The pictures represent all mice of each group. The highlighted parts: blue circle (glomerulus), yellow (tubules), black (proteinaceous cast), red (epithelial cells of tubules), green (inflammatory cells deposited in glomerulus), black arrow (glomerular basement membrane), green arrow (mesangium).

the next observation focus was tubules. Tubules are part of the kidney which can recover from damages. Tubulus in the QUE group has undamaged nucleus and has the regular appearance. The tissue condition around the glomerulus and tubules of QUE group still look unstructured compared to standard (Figure 2c). Furthermore, this detailed assessment was verified by using a semi-quantitative evaluation. The semi-quantitative assessment was done by following Moroni's method $(2016)^{12}$ which focuses on the damage signs of glomeruli in 10 microscope observation fields. According to the assessment, we obtain the data of the change of kidney pathology severity caused by QUE (Table 4). Glomerulus inflammation decreased significantly $(p<0.05)$ in QUE group. The percentage of damaged glomeruli $(>+3)$ is about $1: 8$ compared to the negative control group. This result confirms the detailed assessment and the IL-6 analysis results. At last, the anti-inflammatory effect of QUE was proven to reduce the severity of inflammation sign in lupus nephritis mice.

\section{DISCUSSION}

Quercetin-3-O-rhamnoside (QUE) have a better absorption profile and solubility on the gastrointestinal tract than its aglycone, quercetin. Quercetin has proven to maintain rheumatoid arthritis in a rat model. ${ }^{2,13}$ In this research, we challenged the QUE to treat a severe lupus nephritis mice model and then we measured the biomarkers of $\mathrm{T}$ cell dependent pathway of lupus pathogenesis. At the first biomarker, we found an inspiring result in the $\mathrm{T}$ reg marker of $\mathrm{CD} 4^{+} \mathrm{CD} 25^{+} \mathrm{T}$ cells and FOXP3 $\mathrm{T}$ cells. It increased drastically after receiving QUE for three weeks (Figure 1 and Table 1). T regs profoundly decreased in severe lupus condition, both in lupus patient and lupus mice significantly. The low number and low activity of $\mathrm{T}$ regs impact on the disorganized $\mathrm{T}$ cell regulations which result in the high number of autoreactive $\mathrm{T}$ cells. ${ }^{14,15,16,17}$ Therefore, the
Table 4: The semi-quantitative analysis of kidney of lupus mice based on Moroni's method $(n=10)$.

\begin{tabular}{ccc}
\hline Groups & $\begin{array}{c}\text { The score of kidney } \\
\text { pathology severity } \\
\text { (mean } \pm \text { SD) }\end{array}$ & $\begin{array}{c}\text { The severe inflamed } \\
\text { glomeruli left (+3-+4) (\%) } \\
\text { (mean } \pm \text { SD) }\end{array}$ \\
\hline Negative control & $2.94 \pm 0.18$ & $79 \pm 15.23$ \\
QUE & $1.18 \pm 0.10^{*}$ & $10 \pm 0.00^{*}$ \\
Positive control & $3.16 \pm 0.84$ & $75 \pm 22,73$ \\
\hline
\end{tabular}

*significantly different to the negative control group $(\mathrm{p}<0.05)$ using Oneway ANOVA calculation in SPSS Statistics

auto-reactive T cells attack the healthy cell since the abnormal recognizing of "self". 18,19 The genetic factors might be a cause of this disorder, ${ }^{20,21}$ but there are a lot of factors that also might be contributed in. The factors include molecular mimicry, genetics, and epigenetics. In the previously research, the relative percentage of T regs FOXP3 in mice was lower than normal. The very low $\mathrm{T}$ regs cannot eliminate the high number of auto-reactive T-cell formed in the body, so the glomerulonephritis severity signs increased rapidly. After the period of QUE administration, the fact of QUE increases the T reg number is a positive outcome which beneficially affects on lowering the auto-reactive $\mathrm{T}$ cells so the lupus manifestation can be handled. The glomerulonephritis occurred by the deposition of immune complex. There is a wide variety of immune complexes trapped in the glomerula. It results in inflammation, but not all the glomerula permanently damage. QUE led the inflamed glomerula to return to the occasionally form so it appears as the normal glomerula with the higher function than the inflamed ones.

In severe lupus, auto-reactive $\mathrm{T}$ cells lead the $\mathrm{B}$ cells to produce lupusspecific antibodies. ${ }^{22}$ The lupus-specific antibodies are named by their target, such as anti-dsDNA, anti-histon, anti-C1, etc. However, one of them is not appointed by its target, called anti-Smith (anti-Sm). Anti-Sm trig other auto-antibodies to be produced in an abundant, and then result in the more severe lupus manifestations. ${ }^{23}$ In this research, QUE did not reduce the anti-Sm level significantly. The same effect also happened to the positive control group which received cyclophosphamide. It indicates that QUE mechanism is not by lowering the anti-Sm level. Further investigation is needed to find the other antibodies reduced by QUE.

Nevertheless, the anti-inflammatory might be a core mechanism of the QUE efficacy on severe lupus mice. Therefore, we find that QUE reduces the total IL-6 significantly, reveal the lower cause of inflammation. The low number of pro-inflammatory cytokine will automatically reduce the anti-inflammatory cytokines. ${ }^{24,25}$ This data was confirmed by the histopathology observation which proved that the QUE reduces the glomerulus inflammation.

The effect of QUE on three steps of T cell dependent pathway of lupus pathogenesis studied can be an excellence of QUE than other compounds tested for severe lupus. At last, this study provides a sufficient data about the effect of QUE to reduce lupus manifestations in lupus mice since it increases the number of Tregs FOXP3. It is preciously useful to control the auto-reactive T cell not to damage "self" cells and tissues, and then the QUE can be developed to be a new safe and effective drug for severe lupus, especially lupus nephritis.

\section{CONCLUSION}

QUE has an anti-inflammatory activity which reduces the severity of lupus nephritis signs in lupus mice by initially increasing the $\mathrm{CD} 4^{+} \mathrm{CD} 25^{+}$ and FOXP3 ${ }^{+}$Tregs numbers. QUE is potential to be further developed as a safe treatment choice for lupus nephritis. However, the QUE effects on various lupus auto-antibodies need to be confirmed. 


\section{ACKNOWLEDGEMENT}

We thank Faculty of Pharmacy, Mulawarman University for funding this research by a research grant number of 0734/UN17.12/LT/2017 from DIPA PNBP Faculty of Pharmacy, Mulawarman University.

\section{CONFLICT OF INTEREST}

The authors declare no conflict of interest.

\section{ABBREVIATIONS}

ACR: American College of Rheumatology; CD: cluster of differentiation; FOXP3: Forkhead box pro 3; Kg BW: kilograms per body weight; QUE: Quercetin-3-O-rhamnoside; SLICC: Systemic Lupus Collaborating Clinics.

\section{SUMMARY}

Quercetin-3-O-rhamnoside (QUE) reduces the lupus sign in TMPDtreated lupus mice. QUE increased the relative percentage of $\mathrm{CD} 4{ }^{+} \mathrm{CD} 25^{+}$ Treg and Foxp3 T reg cells significantly. The high T reg number increases the immune controlling mechanism of auto-reactive cells in lupus, so the lupus manifestations can be inhibited.

\section{REFERENCES}

1. Shinoki A, Lang W, Thawornkuno $C$, Kang H, Kumagai $Y$, Okuyama M, et al Short communication A novel mechanism for the promotion of quercetin glycoside absorption by megalo a-1,6-glucosaccharide in the rat small intestine. Food Chem. 2013;136(2):293-6.

2. David AV, Arulmoli R, Parasuraman S. Overviews of Biological Importance of Quercetin: A Bioactive Flavonoid. Pharmacogn Rev. 2016;10(20):84-9. doi: 10.4103/0973-7847.194044.

3. Ahmad I, Yanuar A, Mulia K, Mun A, Mulia K. Application of Ionic Liquid based Microwave-Assisted Extraction of the Secondary Metabolite from Peperomia pellucida (L) Kunth. Pharmacogn J. 2017:9(2):227-34.

4. Terao J. Factors modulating bioavailability of quercetin-related flavonoids and the consequences of their vascular function. Biochem Pharmacol. 2017;139:15-23.

5. Lin $Y$, Yan $Y$, Zhang H, Chen $Y$, He Y, Wang $S$, et al. Salvianolic acid A alleviates renal injury in systemic lupus erythematosus induced by Pristane in BALB/C mice. Acta Pharm Sin B. 2017;7(2):159-66.

6. Indriyanti N, Garmana AN. Ekstrak Daun Cocor Bebek (Kalanchoe pinnata) Untuk Terapi Preventif Lupus pada Mencit yang Diinduksi dengan 2,6,10,14 Tetramethylpentadecane. J Trop Pharm Chem. 2011;1(3):221-6.

7. Ferreira RT, Coutinho MAS, Malvar DDC, Costa EA, Florentino IF, Costa SS, et al. Mechanisms underlying the antinociceptive, antiedematogenic, and antiinflammatory activity of the main flavonoid from Kalanchoe pinnata. Evidencebased Complement Altern Med. 2014;2014.

8. Zhu W, Xu J, Jiang C, Wang B, Geng M, Wu X, et al. Pristane induces autophagy in macrophages, promoting a STAT1-IRF1-TLR3 pathway and arthritis. Clin
Immunol. 2017:175:56-68

9. Bonanni A, Vaglio A, Bruschi M, Sinico RA, Cavagna L, Moroni G, et al. Multiantibody composition in lupus nephritis: Isotype and antigen specificity make the difference. Autoimmun Rev. 2015;14(8):692-702

10. Rehman MU, Tahir M, Ali F, Qamar W, Lateef A, Khan R, et al. Cyclophosphamide-induced nephrotoxicity, genotoxicity, and damage in kidney genomic DNA of Swiss albino mice: The protective effect of Ellagic acid. Mol Cell Biochem. 2012;365(1-2):119-27.

11. Weinstein JS, Delano MJ, Xu Y, Kelly-Scumpia KM, Nacionales DC, Li Y, et al. Maintenance of anti-Sm/RNP autoantibody production by plasma cells residing in ectopic lymphoid tissue and bone marrow memory B cells. J Immunol. 2013;190(8):3916-27.

12. Ayhanci A, Günes S, Sahinturk V, Appak S, Uyar R, Cengiz M, et al. Seleno L-methionine acts on cyclophosphamide-induced kidney toxicity. Biol Trace Elem Res. 2010;136(2):171-9.

13. Haleagrahara N, Miranda-hernandez S, Alim A, Hayes L, Bird G, Ketheesan N. Therapeutic effect of quercetin in collagen-induced arthritis. Biomed Pharmacother. 2017:90:38-46.

14. Moroni G, Depetri F, Ponticelli C. Lupus nephritis: When and how often to biopsy and what does it mean? J Autoimmun. 2016:74:27-40.

15. Huehn J, Beyer M. Epigenetic and transcriptional control of Foxp3 (+) regulatory T cells. Semin Immunol. 2015:27(1):10-8.

16. Lee SK, Kim JY, Jang BW, Hur SE, Na BJ, Lee M, et al. Foxp3high and Foxp3low Treg cells differentially correlate with T helper 1 and natural killer cells in peripheral blood. Hum Immunol. 2011;72(8):621-6

17. Hadaschik EN, Wei $X$, Leiss $H$, Heckmann B, Niederreiter B. Steiner G, et al. Regulatory $T$ cell deficient scurfy mice develop systemic autoimmune features resembling lupus-like disease. Arthritis Res Ther. 2015;17(1):35.

18. Piconese S, Pacella I, Timperi E, Barnaba V. Divergent effects of type-I interferons on regulatory T cells. Cytokine Growth Factor Rev. 2015;26(2):133-41.

19. Li X, Yue Y, Zhu Y, Xiong S. Extracellular, but not intracellular HMGB1, facilitates self-DNA induced macrophage activation via promoting DNA accumulation in endosomes and contributes to the pathogenesis of lupus nephritis. Mol Immunol. 2015;65(1):177-88.

20. Lupus Research Institute. Protein modifications that trigger t cell autoimmunity. Lupus TCIN. 2016;3(1):6-7.

21. Relle M, Weinmann-Menke J, Scorletti E, Cavagna L, Schwarting A. Genetics and novel aspects of therapies in systemic lupus erythematosus. Autoimmun Rev. 2015;14(11):1005-18

22. Tang L, Wang Y, Zheng S, Bao M, Zhang Q, Li J. PTPN22 polymorphisms, but not R620W, were associated with the genetic susceptibility of systemic lupus erythematosus and rheumatoid arthritis in a Chinese Han population. Hum Immunol. 2016;77(8):692-8.

23. Yung $\mathrm{S}, \mathrm{Ng} \mathrm{CYC}$, Ho SK, Cheung KF, Chan KW, Zhang $\mathrm{Q}$, et al. Anti-dsDNA antibody induces soluble fibronectin secretion by proximal renal tubular epithelia cells and downstream increase of TGF- $\beta 1$ and collagen synthesis. J Autoimmun. 2015:58:111-22

24. Shor DB, Blank M, Reuter S, Matthias T, Beiglass I, Volkov A, et al. Anti-ribosomal-P antibodies accelerate lupus glomerulonephritis and induce lupus nephritis in naïve mice. J Autoimmun. 2014;54:118-26

25. Liu X, Fang L, Guo TB, Mei H, Zhang JZ. Drug targets in the cytokine universe for autoimmune disease. Trends Immunol. 2013;34(3):120-8. 